\title{
2006-1296: ELECTRONIC LEARNING AT THE FACULTY OF ENGINEERING, CHULALONGKORN UNIVERSITY
}

\section{Direk Lavansiri, Chulalongkorn University}

Prof. Dr. Direk Lavansiri is the Dean of the Faculty of Engineering at Chulalongkorn University. He earned his Ph.D. in Civil Engineering from Oregon State University in 1977 and joined Faculty of Engineering in 1978. He served as the Director of Continuing Education Center, Chulalongkorn University from 1989 to1999. Email: Direk.L@chula.ac.th

\section{Boonchai Sowanwanichakul, Chulalongkorn University}

Assist. Prof. Boonchai Sowanwanichakul is the Associate Dean of the Faculty of Engineering and Director of the Center for Electronic Learning, Chulalongkorn University. He graduated from Chulalongkorn University in 1978 and joined the Department of Computer Engineering in 1979. Email: Boonchai.so@chula.ac.th

\section{Manoj Lohatepanont, Chulalongkorn University}

Dr. Manoj Lohatepanont is the Deputy Director of the Center for Electronic Learning, Chulalongkorn University. He earned his Sc.D. in Transportation and Logistics Systems from the Massachusetts Institute of Technology in 2002 and joined Faculty of Engineering in 2004. Email: Manoj.L@chula.ac.th 


\title{
Electronic Learning at the Faculty of Engineering, Chulalongkorn University
}

\begin{abstract}
The Faculty of Engineering at Chulalongkorn University recognizes the growing demand for elearning and has developed strategy and implementation plan accordingly. In this paper, we describe the classification of e-learning readiness of the faculty and show a steady progress towards greater e-learning readiness. A strategy map based on the balanced scorecard concept was developed to formalize and guide our implementation of e-learning based courses and programs. We show, in this paper, how all of the four perspectives-stakeholder, process, capacity building, and finance - are balanced in our strategy map. We describe our current major e-learning projects, which comprise of three projects with our international alliance partners, and one project with a domestic network partner.
\end{abstract}

\section{Introduction}

Chulalongkorn University started experimenting with electronic learning (e-learning) more than five years ago by first implementing a learning management system (LMS), which supplemented classroom learning and encouraged faculty members to move class materials into electronic formats. Later, the Center for Academic Resource, its central library, acquired the "Blackboard" learning management system for campus wide usage. In 2002, Chulalongkorn University began offering its first flexible learning undergraduate degree in Software Development as a pilot program. The program was transferred to the Faculty of Engineering in 2005.

Chulalongkorn University's strategic plan dictates that the university increase its role as a major academic institute domestically and internationally by increasing education opportunities through distance learning and other alternative (i.e., non-conventional) means through which students can be educated. It is also a mission of the university to encourage a learning environment in which each student can independently develop knowledge and skills to his/her fullest extent without limitations in terms of place and time of study. To this end, Chulalongkorn University's Faculty of Engineering has devised implementation plan to support the e-learning development as will be described in this paper.

This paper covers:

1. e-learning readiness,

2. e-learning implementation strategy, and

3. plans for building academic cooperation with world-class institutes to achieve knowledge and technology transfer

\section{E-Learning Readiness}

Chulalongkorn University has adopted e-learning as a medium for its distant education, in which instructors and students are located at different geographical locations. In our particular case, the instructors are often based in Bangkok where the university is located and the students are located in distant provinces of Thailand such as the provinces of Naan and Srisaket. The 
program of study and course structure are specifically and carefully designed to allow instructors to cover and demonstrate class materials effectively in distant learning mode and to enable independent learning by students. Various teaching materials and techniques are used.

\subsection{Classification of E-Learning Readiness}

\subsubsection{Classification of E-Learning Readiness by Chulalongkorn University}

To facilitate the transition to a fully functional e-learning program, a gradual transition approach is adopted. In this approach, instructors gradually modify the courses currently offered (or new courses) from conventional, in-class, teaching to e-learning based classes. The classification of e-learning readiness of courses by Chulalongkorn University is as follows ${ }^{1}$ :

1. knowledge database,

2. e-learning enhanced course,

3. e-learning hybrid course, and

4. e-learning based course.

The entry level, knowledge database level, encompasses translating some class materials into electronic format. Those electronic class materials may be stored on servers and later retrieved by students on the network. The class structure is unchanged. There still exist in-class personto-person lectures and/or labs. The electronic class materials are supplementary materials to inclass experience.

At the second level, the e-learning enhanced course, some class materials are translated into electronic format, stored on servers, and retrieved by students on the network. Links to external knowledge databases or sources are provided. Independent online study is part of the class requirement. The class structure is largely unchanged. Instructors and students still meet in classroom. The roles of instructors will focus more on enhancing electronic class materials for independent study and leading in-class discussion.

With e-learning hybrid course, class materials are translated into electronic format, stored on servers, and retrieved by students on the network. Links to external knowledge databases or sources are provided. Significant independent online studies become part of the class requirement. Some class activities, such as discussions and tutorials, are moved online.

The last level, e-learning based course, requires all activities to be done online. At this level, all teachings are done online, without classroom meetings. It enables full-scale distant learning, where instructors and students are located away from one another in space and/or time. Students, however, must be able to reach instructors or tutors conveniently should their needs arise.

\subsubsection{Classification of E-Learning Readiness by Faculty of Engineering}

Noting that the university's classification of Levels 1 and 2 differs only slightly, the Faculty of Engineering adopts a different classification by merging Levels 1 and 2 and introducing a new level to further extend the scope of e-learning implementation. 
The classification of e-learning readiness at the Faculty of Engineering is as follows:

1. e-learning enhanced course,

2. e-learning hybrid course,

3. e-learning based course, and

4. e-learning based program/curriculum.

Levels 1 to 3 are similar to Levels 2 to 4 classified by the university. Level 4, however, extends the scope of e-learning implementation at the Faculty of Engineering further by encouraging the faculty to offer distant learning certificate or degree programs. The (Level 3) e-learning based courses accounts for more than $50 \%$ of the total number of courses taken by students in these $e$ learning based programs.

\subsubsection{Current E-Learning Readiness of the Faculty of Engineering}

The level of e-learning readiness of the faculty is summarized in Table 1 . The faculty has set a growing target for each year of the implementation. In 2008, we plan to have at least 60 elearning based courses, in which all instructions are done electronically. In 2005, we implemented the first e-learning based program in Software Development for students in distant part of the country. We plan to increase the number of e-learning based programs by one program each year from 2006 to 2008, which will bring the total number of e-learning based programs to four.

Table 1 E-learning Readiness Target of the Faculty of Engineering, Chulalongkorn University

\begin{tabular}{|l|c|c|c|c|c|}
\hline \multicolumn{1}{|c|}{ Performance Indicator } & \multicolumn{5}{c|}{ Academic Years } \\
\cline { 2 - 6 } & 2004 & 2005 & 2006 & 2007 & 2008 \\
\hline $\begin{array}{l}\text { Ratio of e-learning enhanced courses to the total number of } \\
\text { undergraduate courses (excluding lab courses) }\end{array}$ & $10 \%$ & $20 \%$ & $40 \%$ & $50 \%$ & $60 \%$ \\
\hline $\begin{array}{l}\text { Ratio of } e \text {-learning hybrid courses to the total number of } \\
\text { undergraduate courses (excluding lab courses) }\end{array}$ & $5 \%$ & $10 \%$ & $20 \%$ & $30 \%$ & $40 \%$ \\
\hline Total number of $e$-learning based courses & 5 & 10 & 20 & 40 & 60 \\
\hline Total number of e-learning based programs & - & 1 & 2 & 3 & 4 \\
\hline
\end{tabular}

\section{E-Learning Implementation Strategy}

The Faculty of Engineering has applied the balanced scorecard principle to the development of its e-learning implementation strategy in order to ensure quality development and adhere to its Quality Assurance Program ${ }^{2}$. Conventional strategic planning focuses on some common goal (e.g., profit) and include standard analyses (e.g., SWOT analysis), which eventually lead to vision and mission of the organization. The balanced scorecard methodology, however, focuses equally on four important perspectives ${ }^{3}$ :

- stakeholder perspective,

- process perspective,

- capacity building perspective, and

- financial perspective. 
Applying the balanced scorecard methodology, the Faculty of Engineering has developed its strategy map, displaying the relationships of these four perspectives as shown in Figure 1.

The stakeholder here is defined as students who receive the education. The focuses in the stakeholder perspective are the students' satisfaction with the quality of the programs offered and their ability to receive the education as if they were learning face-to-face with instructors.

2. Process

1. Stakeholder

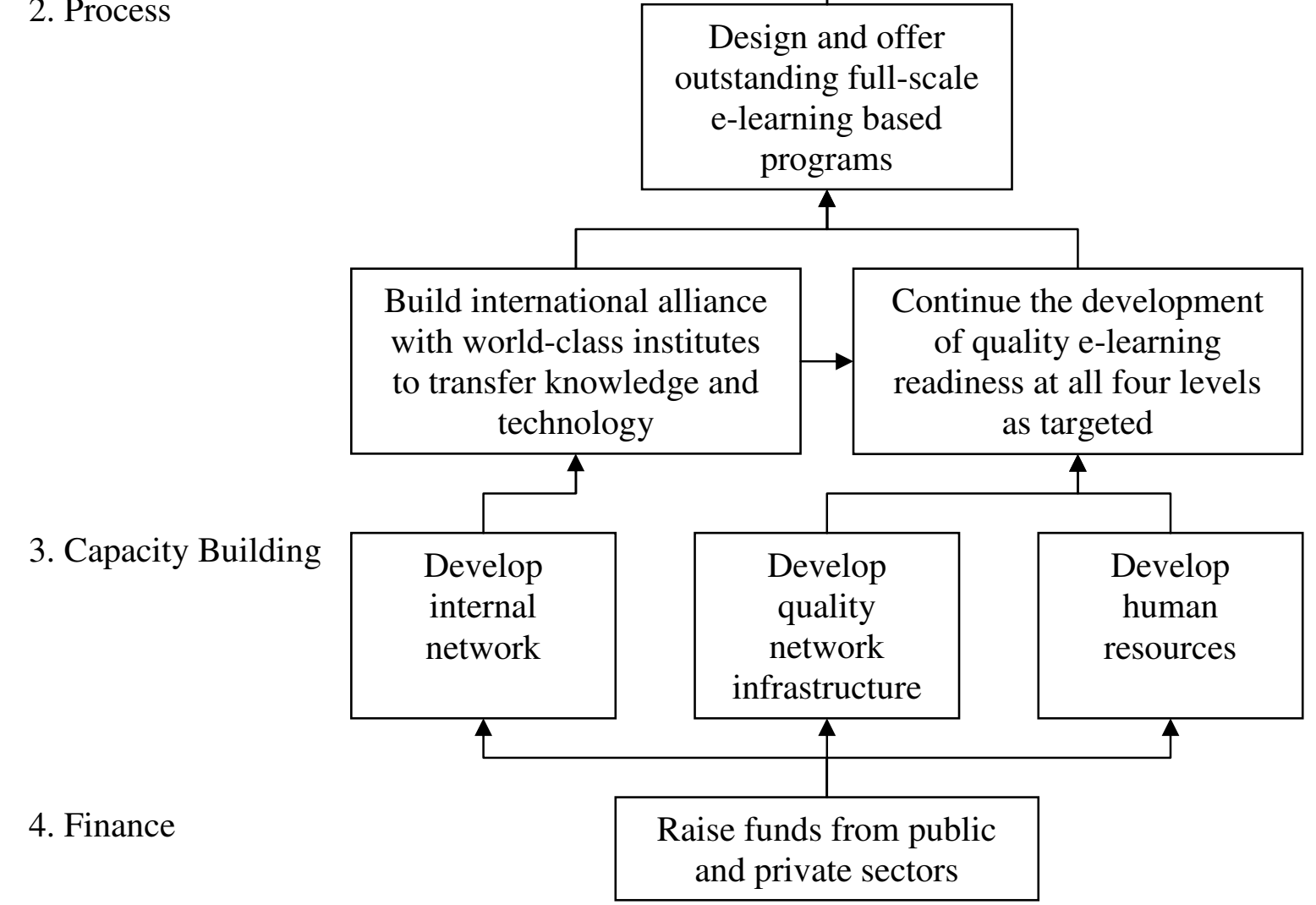

Figure 1 Strategy Map for E-Learning Implementation Strategy at the Faculty of Engineering, Chulalongkorn University

In the process perspective, the faculty has developed three processes:

1. academic alliance building process,

2. knowledge and technology transfer process, and

3. e-learning based program design and implementation process.

The faculty recognizes the importance of building academic alliance with world-class institutes in order to learn and share experience and expertise. Once the alliance is setup, the transfer of 
knowledge and technology can begin; this transfer leads to the improvement of our in-house capability. The two processes described form the basis of the development of quality e-learning based programs.

From the capacity building perspective, the Faculty of Engineering focuses on:

1. developing its internal network,

2. developing quality network infrastructure, and

3. developing its human resources.

The faculty aims to synergize internal strengths from its twelve departments, which can provide the knowledge in various engineering fields, and its computer center, which provides information technology supports. The faculty also recognizes the importance of quality network infrastructure. It plans to invest heavily on the equipment both at the faculty and at remote sites, as well as in broadband network connectivity infrastructure. Another major capacity building task is on developing in-house staff who can assist faculty members by putting class materials into electronic format for them, as well as encouragining faculty members who would like to create e-learning materials by themselves.

From financial perspective, all of the mentioned activities require significant funding. The faculty has developed plans to raise sufficient funds from public and private sources to cover the expenses and investments to ensure successful implementation of its e-learning programs.

\section{International Alliance Projects and Current E-Learning Projects}

As part of its e-learning strategy, Chulalongkorn University's Faculty of Engineering has begun building international academic alliance network with world-class institutes. In this section, we describe some of our alliance activities. Also, we describe other ongoing e-learning projects at the faculty.

\subsection{MIT's OpenCourseware Project}

The Faculty of Engineering has singed a pilot agreement with the Massachusetts Institute of Technology to translate MIT's OpenCourseware (OCW), which is MIT's open educational resource containing select MIT course materials, into the Thai language. The Faculty of Engineering has begun translating the materials into Thai, and published the materials online for students and the public at large to access for free at their convenience (Figure 2).

The Faculty of Engineering is also actively building an alliance network for our MIT's OpenCourseware Project. Currently, we are in discussion with several organizations who are interested in joining force to translate MIT materials into Thai. 


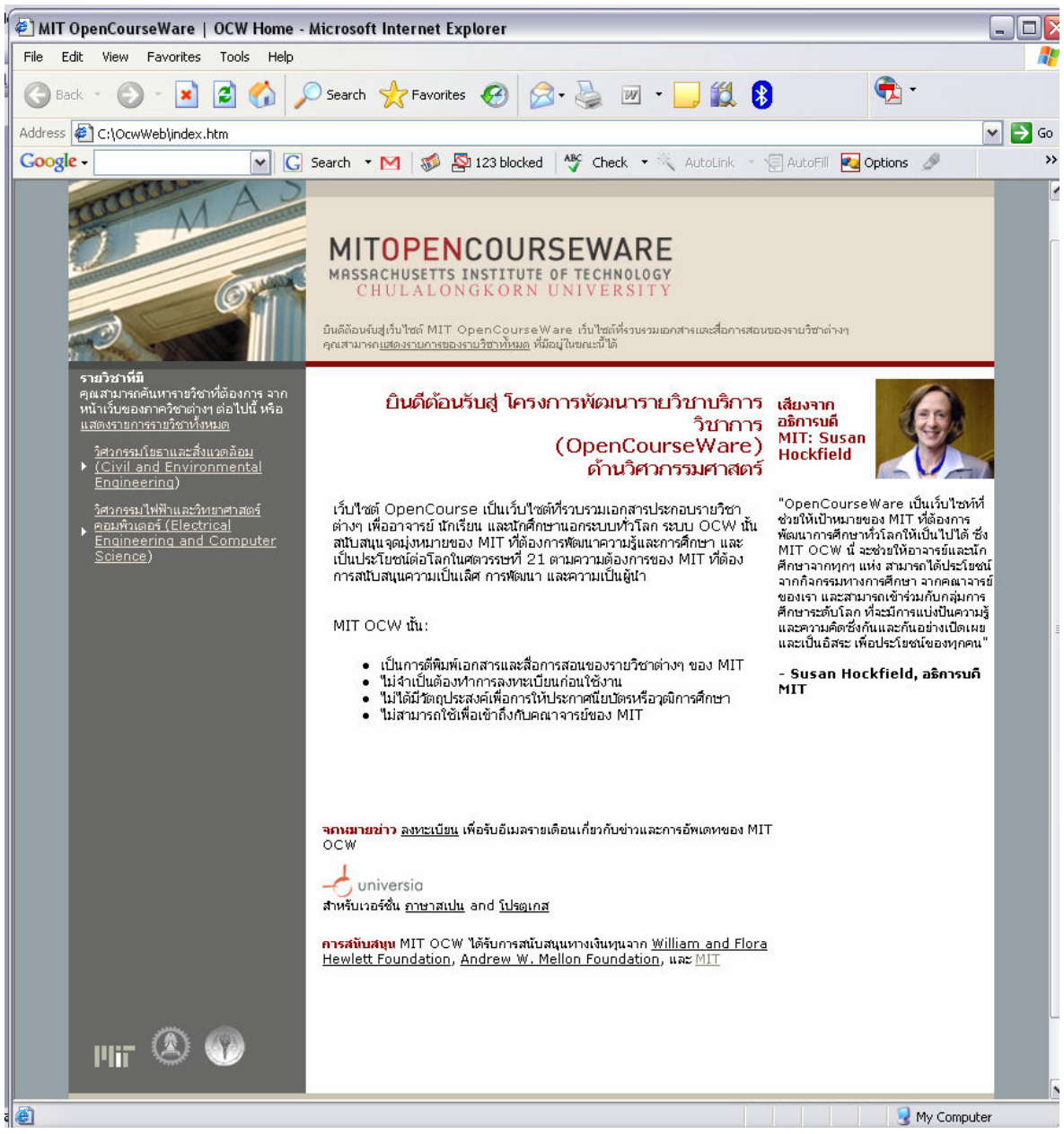

Figure 2 The Homepage of Thai OCW at Chulalongkorn University

\subsection{School on Internet in Asia Project (SOI Asia)}

SOI ASIA Project utilizes satellite based internet to provide internet environment in a less expensive, easy to deploy, and more feasible way for the universities located in Asia in giving and receiving lectures. As of April 2005, 17 universities and research institutes in 11 countries in Asia have joined this project (Figure 3). Chulalongkorn University has a facility to receive lectures via a satellite antenna and respond back through existing campus internet infrastructure (Figure 4). Our students have participated in various courses, for example, Information Technology, Biotechnology, and Marine Science. And in response to the December 2004 Tsunami, Chulalongkorn University organized a lecture series on tsunami disaster and provided tsunami-related lectures through this network. 


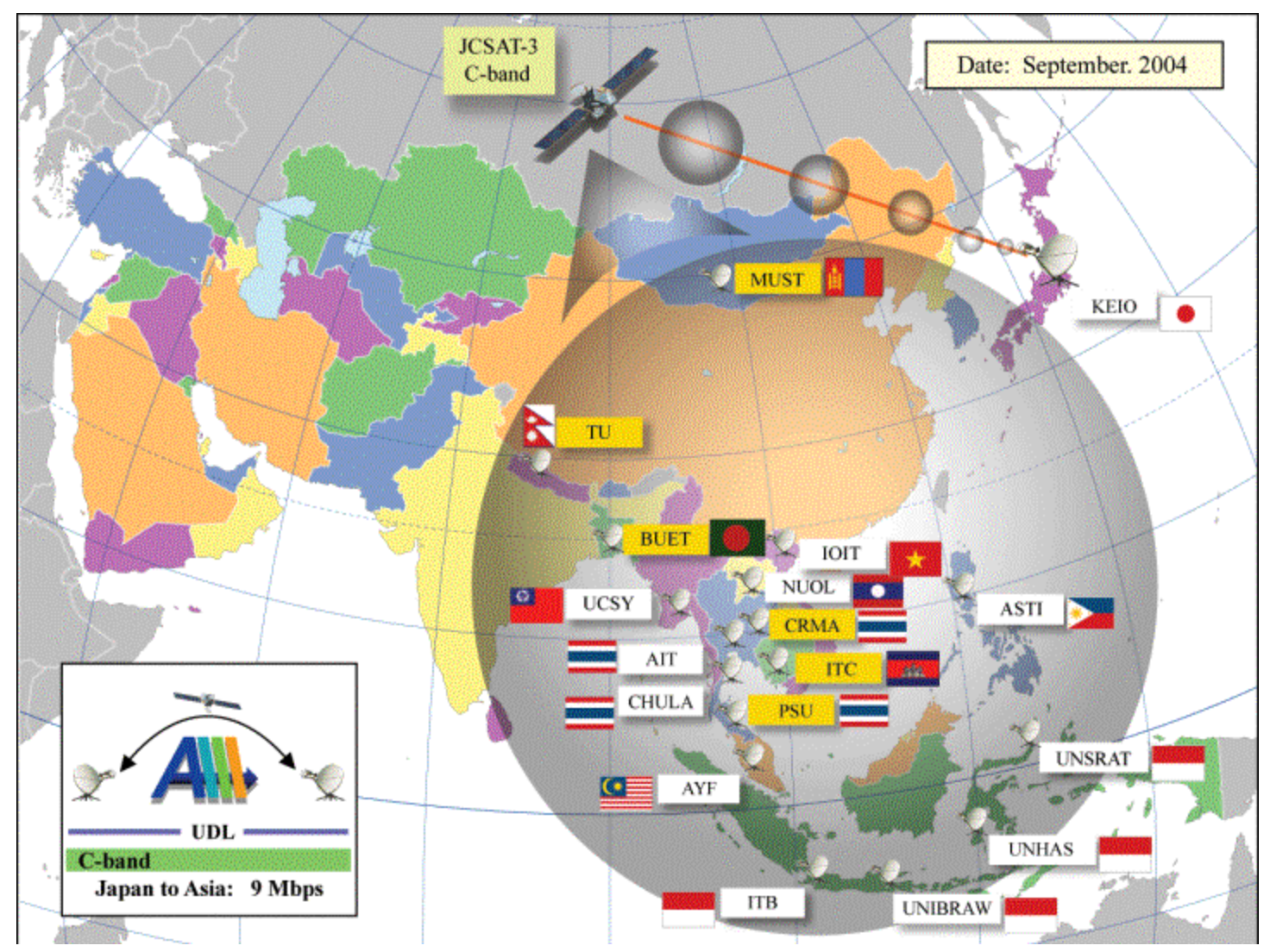

Figure 3. SOI Asia Network Partners

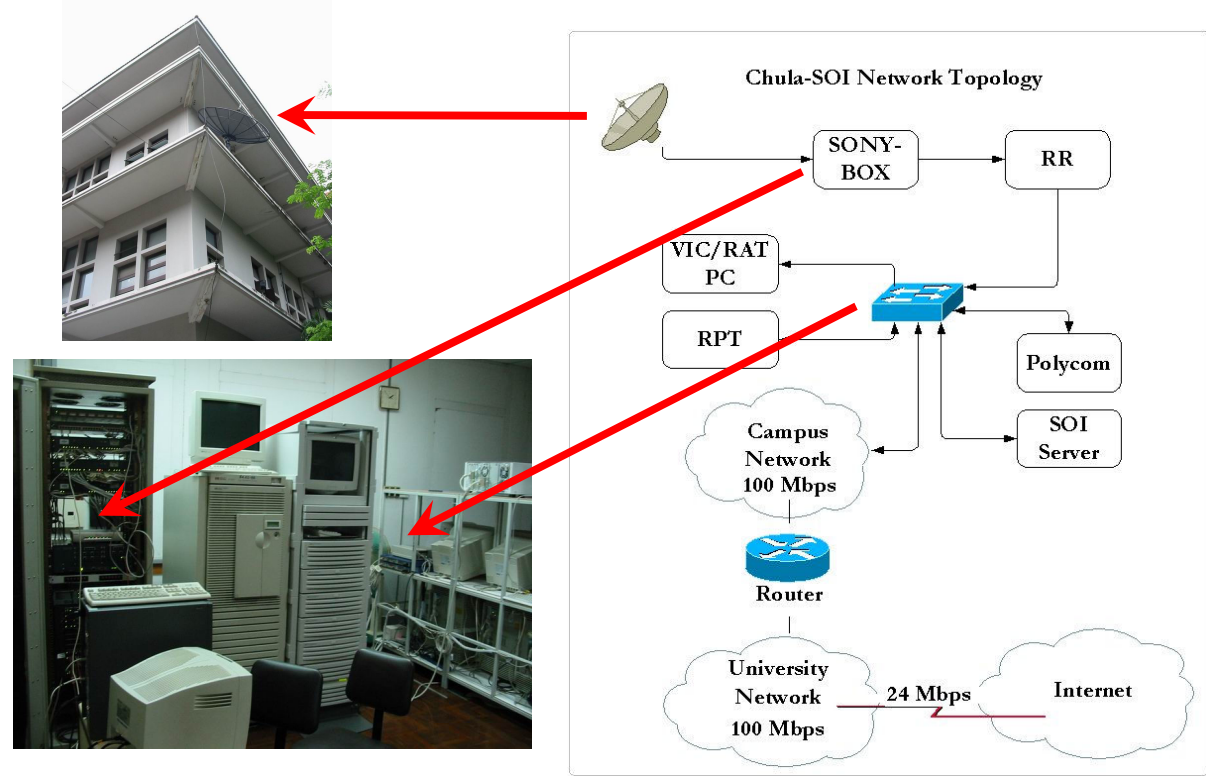

Figure 4. Infrastructure for SOI Asia project at Chulalongkorn University

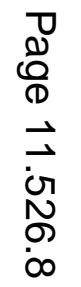




\subsection{Distant Learning Project (D-Learning)}

The Center for Urban Earthquake Engineering, Tokyo Institute of Technology and Department of Civil Engineering, Chulalongkorn University has jointly developed a Distant Learning Program for graduate students. The lectures are done interactively through the internet utilizing also TV conference facilities (Figure 5). Group discussions are held in classroom at both ends and transmitted through the internet to the other classroom. The "Earthquake and Tsunami Disaster Reduction" program was initiated in December 2005. It offers the following courses:

1. Earthquake Ground Motion,

2. Earthquake-induced Disaster,

3. Tsunami Science,

4. Risk Management,

5. Real-Time Information,

6. Earthquake Hazard Mitigation, and

7. Tsunami Hazard Mitigation.

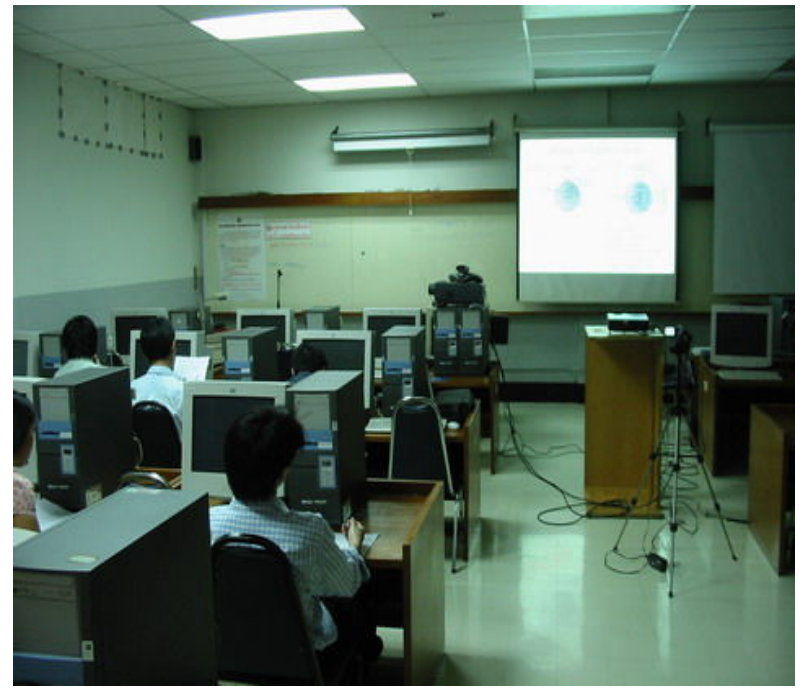

(a) Classroom at Chulalongkorn University

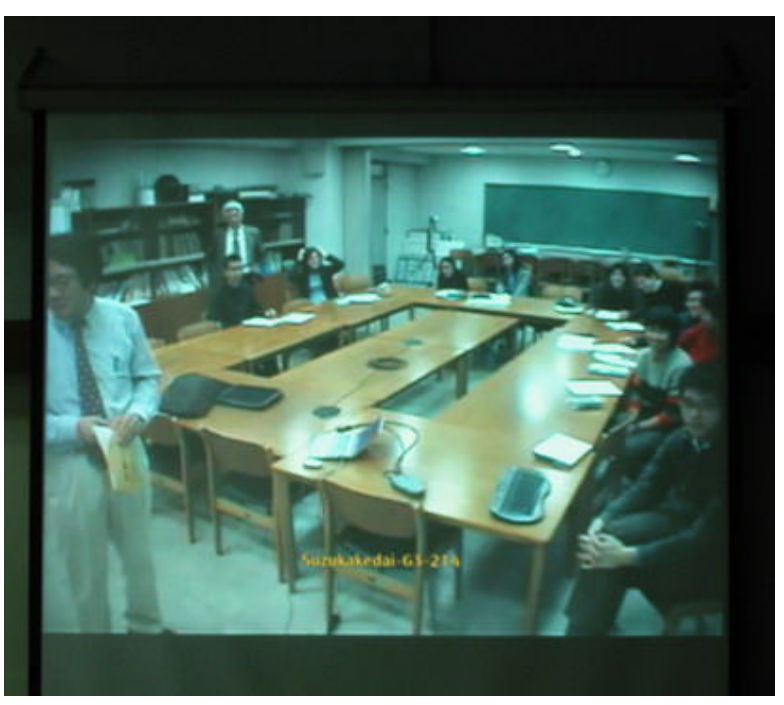

(b) Classroom at Tokyo Institute of Technology

Figure 5 Classroom Environment in D-Learning Project

\subsection{Thai Cyber University Project}

The Commission of Higher Education, Ministry of Education, Thailand has initiated a large scale distant learning project called, "Thai Cyber University." In this project, the Commission of Higher Education seek cooperation from Thai and international universities to offer e-learning courses for self-learning students, who can register and take classes at their convenient time and place. Students must hold a bachelor degree in related field of study. That is, the degrees offered by Thai Cyber University will be students's second (or later) degrees. The program is designed in this fashion in recognition of our inability to provide fundamental laboratory courses, such as Physics or Chemistry. Students will have had taken these classes in conventional system prior to enrolling with Thai Cyber University. 
The learning in the program will be monitored through a learning management system to ensure quality of the education. Group discussions will be held through the internet webboard. Some programs of study will employ local tutors, who can help students and act as contact points between lecturers and students, in major areas throughout the country. After completion of all course requirements, the students will be given credits for the course. And after completing a specified list of courses and accumulating necessary credits, the students can graduate with a degree or certificate of study. The Faculty of Engineering has participated in this project by offering several e-learning based courses and has plan to offer certificate programs in the near future.

Note, however, that the current capacity of the network infrastructure is limited and cannot handle large number of students. Additional investments in network infrastructure and equipments have been made to upgrade the current system to a design capacity of five hundred simultaneous users at each local node. We recognize that the demand on the systems can grow much larger and are developing plans to handle future demand.

\section{Summary}

In this paper, we describe Chulalongkorn University's Faculty of Engineering's vision and implementation of electronic learning system. We show our current level of e-learning readiness and outline our development plan to increase our readiness based on the balanced scorecard principle. The plan begins from securing sufficient funding from different sources. In the plan, we emphasize the development of internal capacities synergizing talents and skills of our twelve departments, as well as the developments of network infrastructure and human resources. The plan also outlines our cooperation with international institutes, recognizing the borderless nature of e-learning philosophy. All of these were done to ensure the highest quality of education for students.

We describe the implementations, problems and solutions of four of our current projects-three with our international alliance partners and one with a domestic network partner. The problems that we face are the inability to offer laboratory based courses and the inability to handle very large number of students. For the former, we circumvent the problem by offering only courses that require no or limited access to laboratories and avoiding altogether courses that require heavy equipment laboratories; as a result, we can only offer degrees to students as continuing or second degrees. For the latter, we have made significant investments to improve the network infrastructure to enable us to handle relatively large number of students. We recognize, however, that continued investments and developments are needed to handle future demand as the systems grow.

\section{Bibliography}

1. Chulalongkorn University (2004) Chulalongkorn University's E-Learning and Distant Learning Projects, Internal Paper, Chulalongkorn University, Bangkok, Thailand. 
2. Direk Lavansiri and Sucharit Koontanakulvong (2005) "Use of CUQA in Quality Assurance System of Faculty of Engineering, Chulalongkorn University," The $4^{\text {th }}$ ASEE/AaeE Global Colloquium on Engineering Education, 26-29 September 2005, Sydney, Australia.

3. Robert S. Kaplan and David P. Norton (2004) Strategy Maps: Converting Intangible Assets into Tangible Outcomes, Harvard University Press, USA. 